\title{
Short communication: Chia seed extract enhances physiochemical and antioxidant properties of yogurt
}

\author{
H. C. Kwon, H. Bae, H. G. Seo, and S. G. Han* \\ Department of Food Science and Biotechnology of Animal Resources, Konkuk University, Seoul 05029, Republic of Korea
}

\begin{abstract}
Yogurt is a healthy dairy food fermented by lactic acid bacteria (LAB). Because consumers demand healthier and more nutritious yogurt, numerous substances have been used to supplement yogurt. Chia seed has been reported to contain abundant phenolic compounds, dietary fiber, and n-3 fatty acids and therefore is a potential functional food additive. The aim of this study was to investigate the influence of chia seed extracts on the physicochemical and bioactive properties of set-type yogurt. Yogurt was fortified with chia seed water extract (CSWE) or chia seed ethanol extract (CSEE) at 0.05 or $0.1 \%$ (vol/vol). Results showed that supplementation with CSWE or CSEE significantly accelerated the fermentation rate and growth of LAB. Both CSWE and CSEE improved the viscosity, syneresis, and water-holding capacity of yogurt. The radical scavenging activity of yogurt was increased with both extracts, and the 0.1\% CSEE yogurt exhibited the highest radical scavenging activity. Furthermore, 0.1\% CSEE yogurt significantly inhibited lipopolysaccharideinduced production of hydrogen peroxide in human colon cells. Addition of chia seed extract improves the growth of LAB, the physiochemical properties, and the health-beneficial effects of set-type yogurt.
\end{abstract}

Key words: yogurt, chia seed, lactic acid bacteria, functional foods

\section{Short Communication}

Yogurt is a well-known dairy food produced by fermentation of milk with lactic acid bacteria (LAB). Because bioactive peptides are produced by LAB during yogurt fermentation, yogurt has higher biological activity than milk (Pessione and Cirrincione, 2016). Specifically, some peptides in yogurt have antioxidant activities such as inhibition of lipid peroxidation and radical removal (Sah et al., 2014; Nielsen et al., 2017).

Received December 9, 2018.

Accepted March 1, 2019.

*Corresponding author: hansg@konkuk.ac.kr
Recent consumer trends have shown that consumption of healthful food supports healthy lifestyles and reduces the risk of disease (Asioli et al., 2017). These changes in consumer demand have driven the food industry to develop functional foods with health-beneficial effects (Vecchio et al., 2016). Thus, yogurt per se is not usually considered a rich source of bioactive ingredients (Ozturkoglu-Budak et al., 2016). The development of more nutritious yogurt is an ongoing topic in dairy science.

Chia (Salvia hispanica L.) is native to a region from western Mexico extending to northern Guatemala and has been consumed for about 5,500 years (Ullah et al., 2016). Chia seed contains a high amount of dietary fiber and antioxidants derived from phenolic compounds and PUFA (Sargi et al., 2013). Previous studies have shown that chia seed exhibits various beneficial health effects because of its antioxidant, anti-inflammatory, and cardioprotective activities (Ullah et al., 2016). Because of these health effects, chia seed is a potential bioactive ingredient for use in functional foods. In fact, chia seed has been used to manufacture bread, frankfurters, and yogurt (Coelho and de las Mercedes Salas-Mellado, 2015; Pop et al., 2015; Pintado et al., 2016). In yogurt manufacture, supplementation with $1.4 \%$ chia seeds improved the viability of probiotic bacteria during 21 d of shelf life (Pop et al., 2015). However, no study has yet evaluated the effects of chia seed on physicochemical and antioxidant properties of yogurt. Therefore, the aim of this study was to characterize (1) fermentation and physicochemical properties, and (2) bioactive features of chia seed-supplemented yogurt.

Chia seed (Organica Inc., Seoul, Korea) was ground to prepare chia seed extracts (CSE). Chia seed water extract (CSWE) was prepared by heating chia seed in distilled water $(5 \% \mathrm{wt} / \mathrm{vol})$ at $95^{\circ} \mathrm{C}$ for $1 \mathrm{~h}$. Chia seed ethanol extract (CSEE) was prepared by adding chia seed to $70 \%$ ethanol (5\% wt/vol) with stirring for $24 \mathrm{~h}$, at room temperature. The filtered extracts were concentrated with a rotary vacuum evaporator (Tokyo Rikakikai Co. Ltd., Tokyo, Japan). The residue was freeze-dried and stored in deep freezer at $-80^{\circ} \mathrm{C}$ until further use. To prepare yogurts, CSWE and CSEE (0.05 
and $0.1 \%$, wt $/$ wt) were added to $12 \%$ nonfat milk. The mixture was pasteurized at $85^{\circ} \mathrm{C}$ for $30 \mathrm{~min}$ and cooled to $42^{\circ} \mathrm{C}$. The LAB starter included a mixture of Lactobacillus acidophilus (35\%), Streptococcus thermophilus (35\%), and Bifidobacterium longum (30\%; Samik Dairy and Food Co. Ltd., Seoul, Korea). The starter culture was prepared by adding $0.34 \mathrm{~g}$ of LAB starter culture powder to $100 \mathrm{~mL}$ of $12 \%$ nonfat milk. Yogurts were inoculated with $3.5 \%$ yogurt starter culture ( $\mathrm{vol} / \mathrm{vol}$ ). Yogurt was incubated at $42^{\circ} \mathrm{C}$ until the $\mathrm{pH}$ reached 4.6. During the fermentation period, LAB were enumerated using the spread plate method by sequentially diluting with peptone water to the desired dilution factor on selective agar medium. Lactobacillus acidophilus was cultured on de Man, Rogosa, and Sharpe (MRS) agar (Difco Laboratories, Detroit, MI) supplemented with $0.15 \%$ bile salts $(0.1 \mathrm{~g} / \mathrm{mL}$; Oxoid, Basingstoke, UK). Streptococcus thermophilus was cultured on M17 agar (Oxoid) supplemented with $0.5 \%$ lactose (Samchun, Seoul, Korea). Bifidobacterium longum was cultured on MRS-LP agar supplemented with $0.3 \%$ lithium chloride, $0.05 \%$ L-cysteine hydrochloride $(0.1 \mathrm{~g} / \mathrm{mL})$, and $0.9 \%$ sodium propionate (Sigma-Aldrich, St, Louis, $\mathrm{MO})$. Each strain was incubated at $37^{\circ} \mathrm{C}$ for $48 \mathrm{~h}$ under aerobic ( $L$. acidophilus and S. thermophilus) or anaerobic (B. longum) conditions. Acidification kinetics were estimated as described previously (Oh et al., $2016)$. The maximum acidification rate $\left(\mathbf{V}_{\max }\right)$ was calculated based on the variation in $\mathrm{pH}$ over time $(\mathrm{dpH} /$ $\mathrm{dt}$ ), expressed in $\mathrm{pH}$ units $\times 10^{-3} / \mathrm{min}$. At the end of fermentation, the following kinetic parameters were calculated: time taken to reach $\mathrm{V}_{\max }\left(\mathbf{t}_{\max } ; \mathrm{h}\right)$; time taken to reach pH $5.0\left(\mathbf{t}_{\mathrm{pH}} \mathbf{5 . 0} ; \mathbf{h}\right)$; and time taken to complete fermentation $\left(\mathbf{t}_{\mathrm{f}} ; \mathrm{h}\right)$. The $\mathrm{pH}$ of all yogurt samples was determined using a $\mathrm{pH}$ meter (Mettler-Toledo, Columbus, $\mathrm{OH})$.

Syneresis and water-holding capacity (WHC) were determined as described previously (Amaya-Llano et al., 2008; Ünal and Akalin, 2013). Ten grams of yogurt sample was centrifuged at $500 \times g$ for $5 \mathrm{~min}$ and the supernatant was poured off and weighed. Viscosity was measured using a DV-E Viscometer (Brookfield, Toronto, ON, Canada). Next, $35 \mathrm{~g}$ of sample was transferred to a $50-\mathrm{mL}$ conical tube and measured after 5 min of immersion at $50 \mathrm{rpm}$ using a viscometer 63 spindle, and measured at 1-min intervals up to $8 \mathrm{~min}$. The color parameters lightness $\left(\mathbf{L}^{*}\right)$, red-green color $\left(\mathbf{a}^{*}\right)$, and yellow-blue color $\left(\mathbf{b}^{*}\right)$ of yogurts were measured using a colorimeter (Konica Minolta Inc., Tokyo, Japan). Radical scavenging activity was tested using 2,2-diphenyl-1-picrylhydrazyl (DPPH) and 2,2'-azinobis (3-ethylbenzothiazoline-6-sulphonic acid) (ABTS) as described previously (Zhang et al., 2019). Total phenolic compounds (TPC) were estimated as described previously, with minor modifications (Kabir et al., 2015). Briefly, a yogurt extract $(30 \mu \mathrm{L})$ diluted with $120 \mu \mathrm{L}$ of distilled water was blended with $30 \mu \mathrm{L}$ of Folin-Ciocalteu reagent and $30 \mu \mathrm{L}$ of sodium carbonate in a 96 -well plate. The plate was incubated at room temperature for $30 \mathrm{~min}$ in the dark. The absorbance of the sample was measured at $595 \mathrm{~nm}$.

Human colon cells (HT-29) were cultured in RPMI1640 medium supplemented with $10 \%$ fetal bovine serum and $1 \%$ penicillin-streptomycin. To measure the intracellular production of reactive oxygen species (ROS), cells were grown to approximately $80 \%$ confluency in a 6 -well plate. Cells were pretreated with yogurt extracts for $15 \mathrm{~h}$, followed by treatment with LPS (1 $\mu \mathrm{g} / \mathrm{mL}, 24 \mathrm{~h}$ ) to induce production of ROS. The cells were incubated with $2^{\prime}, 7^{\prime}$-dichlorofluorescin diacetate (DCF-DA; $10 \mu M, 30 \mathrm{~min}$ ). Fluorescence intensity was detected using a fluorescent microscope (Eclipse Ti2-U, Nikon Co. Ltd., Tokyo, Japan).

Data were expressed as means \pm standard errors of the mean. Statistical significance was confirmed with SPSS-PASW statistics software for Windows (version 18.0; SPSS, Chicago, IL) by one-way ANOVA and Tukey's post hoc test. $P$-values $<0.05$ were considered to indicate a statistically significant difference.

The results showed that the $\mathrm{pH}$ of CSE-supplemented yogurts (i.e., containing CSWE and CSEE) was markedly lower during fermentation than that of control yogurt without added extracts (Figure 1A). In terms of acidification, supplementation of CSE significantly reduced the fermentation time of yogurt (Figure 1B). Addition of $0.1 \%$ CSWE and CSEE showed a 1.6-fold increase in $\mathrm{V}_{\max }$ and a decrease in $\mathrm{t}_{\max }$. In addition, both $t_{\mathrm{pH} 5.0}$ and $t_{f}$ were decreased by CSE supplementation. Plant or seed extracts have positive effects on yogurt fermentation. Yogurt supplemented with 3\% amaranth seed and red ginseng extract resulted in a rapid decrease in $\mathrm{pH}$ compared with control yogurt (Dimitrova and Kartalska, 2015; Jung et al., 2016). Addition of green tea also reduced fermentation time in a set-type yogurt (Jeong et al., 2018), probably because specific active ingredients derived from the plant or seeds played a prebiotic role and promoted growth of LAB. Therefore, in the current study, we determined the growth rate of each LAB. An increase in LAB results in a rapid decrease in $\mathrm{pH}$ during yogurt fermentation (Aryana and McGrew, 2007). During the fermentation period, counts of L. acidophilus, S. thermophilus, and B. longum were markedly higher in both CSWE and CSEE yogurts than in control yogurt (Figure $1 \mathrm{C}-\mathrm{E}$ ). Counts of $S$. thermophilus and B. longum were dynamically increased at $2 \mathrm{~h}$ in yogurt supplemented with CSWE or CSEE. In particular, the addition of CSE enhanced $L$. acidophilus counts at the end of fermentation $(6$ 
h). The growth of LAB may be promoted by prebiotic components (Pandey et al., 2015). Chia seed is reported to be rich in polyphenolic compounds, mainly chlorogenic acid $\left(7.1 \times 10^{-3} \mathrm{~mol} / \mathrm{kg}\right)$, caffeic acid $(6.6$ $\left.\times 10^{-3} \mathrm{~mol} / \mathrm{kg}\right)$, and myricetin $\left(3.1 \times 10^{-3} \mathrm{~mol} / \mathrm{kg}\right)$ (Muñoz et al., 2013; Pellegrini et al., 2018). A study showed that polyphenols and phenolic extracts derived from plants and seeds increase the growth of colonic bacteria (Peluso et al., 2014). In detail, chlorogenic acid and caffeic acid derived from plant leaf extracts can increase the viability of LAB during yogurt fermentation (Oh et al., 2016). The addition of chlorogenic acid to a batch culture vessel significantly increased the viability of Bifidobacterium spp. (Santana-Gálvez et al., 2017). In contrast, myricetin can be hydrolyzed to glucose or galactose, which provides energy to bacteria ( $\mathrm{Li}$ et al., 2016). In fact, most dietary polyphenols (90-95\%) reach the colon, where polyphenol metabolism is mediated by colonic bacteria (i.e., Lactobacillus spp. and Bifidobacterium spp.; Cardona et al., 2013). Our data support the role of polyphenols in the growth of LAB: the TPC in CSE-added yogurts were significantly increased in a dose-dependent manner (Figure 2A). These data suggest that polyphenols in CSE increased the viable counts of $L$. acidophilus, $S$. thermophilus, and B. longum.

The characteristics of chia seed yogurts are listed in Table 1. The color of yogurt is one of the crucial sensory characteristics (García-Pérez et al., 2005). Addition of CSWE decreased the brightness $\left(\mathrm{L}^{*}\right)$ of yogurt, whereas CSEE increased the redness $\left(a^{*}\right)$ of yogurt. In addition, supplementation of both CSE increased yellowness $\left(b^{*}\right)$. The viscosity of $0.1 \%$ CSWE and $0.1 \%$ CSEE yogurts increased significantly, by 14.78 and $21.32 \%$, respectively, compared with that of control yogurt $(P$ $<0.05)$. Similarly, the addition of polyphenols derived from blackcurrants increased the viscosity compared with control yogurt (Sun-Waterhouse et al., 2013). Syneresis is the extraction of liquid from the yogurt gel matrix and it leads to the separation of whey. Waterholding capacity is the amount of water possessed by the hydrated sample following application of an external force. Both syneresis and WHC are important physical values characterizing yogurt because whey separation on the surface of yogurt may negatively affect consumer perception of the yogurt (Sah et al., 2016). The syneresis values of CSWE and CSEE yogurts were significantly lower than those of the control yogurt $(P$ $<0.05)$. As shown in Table 1, significant differences existed in WHC between yogurts supplemented with CSE and the control yogurt $(P<0.05)$. The highest WHC was observed with $0.1 \%$ CSWE yogurt $(69.6 \%$ ), which was 6.1 percentage units higher than that of control yogurt (63.5\%). Rheological properties (i.e., viscosity) and syneresis of yogurt can be affected by the amounts and properties of proteins (Zare et al., 2011). Proteins are derivatized with polyphenols, and the reactivity of polyphenols depends on the position and number of hydroxyl groups. In fact, the major polyphenols of chia seed - chlorogenic and caffeic acids - exhibit high reactivity with proteins (Rawel et al., 2002), which improves the affinity between milk proteins, resulting in their cohesion (Ozdal et al., 2013). In previous studies, supplementation of yogurt with green coffee seeds that contained 4.1 to $11.3 \mathrm{~g}$ of chlorogenic acid/100 g improved syneresis by stabilizing the gel structure (Dönmez et al., 2017). Both viscosity and WHC are significantly increased in yogurt supplemented with green tea, which is rich in polyphenols (Jeong et al., 2018). In summary, supplementation with CSE improves the physical characteristics of yogurt by increasing the polyphenol content and stabilizing the gel matrix in yogurt.

To evaluate the antioxidant effects of CSE yogurt, we evaluated the levels of TPC and antioxidant activity in CSE yogurts (Figure 2). The TPC was increased by a dose-dependent addition of CSWE or CSEE in yogurt (Figure 2A). The 0.1\% CSWE and 0.1\% CSEE treatments increased TPC by $15.9 \%$ [57.00 $\mu \mathrm{g}$ of gallic acid equivalents (GAE) $/ \mathrm{mL}$ ) and $30.6 \%(64.20 \mu \mathrm{g}$ of GAE/ $\mathrm{mL})$, respectively, compared with control yogurt (49.2 $\mu \mathrm{g}$ of $\mathrm{GAE} / \mathrm{mL}$ ). The antioxidant activities of CSWE and CSEE were measured using a radical scavenging assay (Figure 2B and C). Radical scavenging activity of both DPPH and ABTS increased by $24.3 \%(0.1 \%$ CSEE) and $15.1 \%$ (0.1\% CSEE), respectively (both $P<0.05)$, compared with controls. We also evaluated the antioxidant effect of CSE yogurt in human colon cancer epithelial cells. Generation of intracellular ROS was detected using the fluorescent dye DCF-DA (Figure 2D). Treatment of cells with LPS significantly increased the level of ROS compared with control $(P<$ $0.05)$. However, pretreatment with yogurts containing $0.1 \%$ CSWE and 0.1\% CSEE decreased LPS-induced ROS production. Antioxidant properties of CSE yogurt as shown by TPC and radical scavenging activity are likely responsible for the lower ROS production observed in cells. Control yogurt without CSE also decreased cellular ROS generation. These findings are consistent with the results of assays where yogurt with and without CSE showed strong radical scavenging activity (Figure 2B and C). Excessive generation of ROS in the gastrointestinal tract causes oxidative stress, resulting in diseases such as inflammatory bowel disease (IBD; Bhattacharyya et al., 2014). Chia seed contains abundant polyphenols and PUFA with antioxidant activity because of the presence of components such as $\alpha$-linolenic acid, chlorogenic acid, and caffeic 
(A)

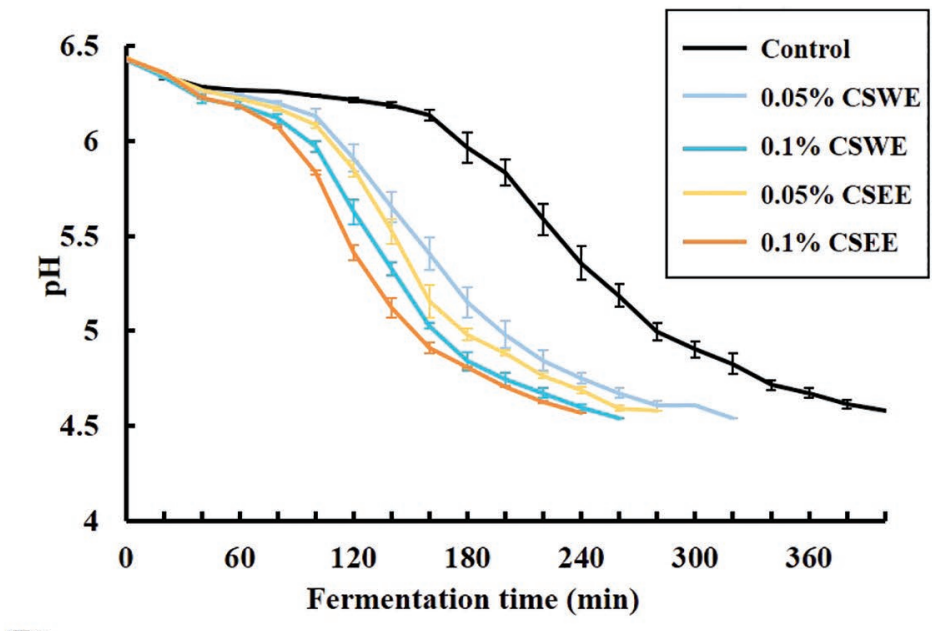

(B)

\section{Kinetic parameter}

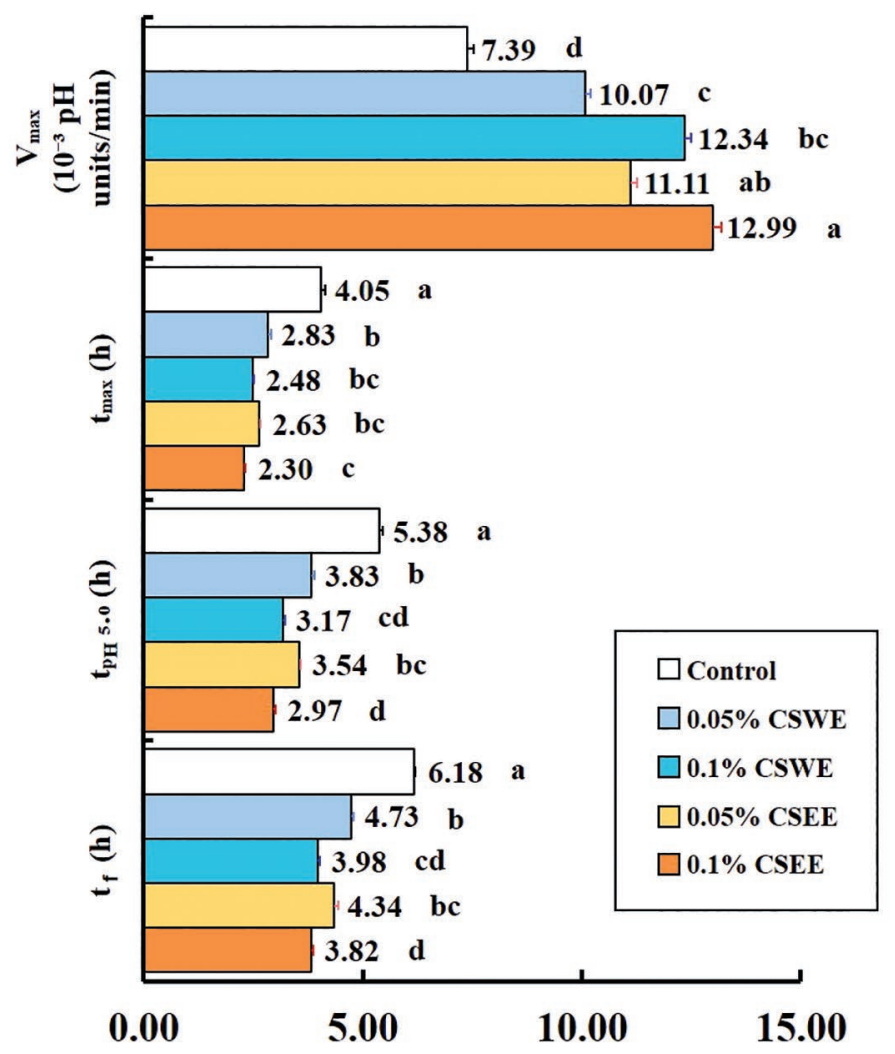

(C)

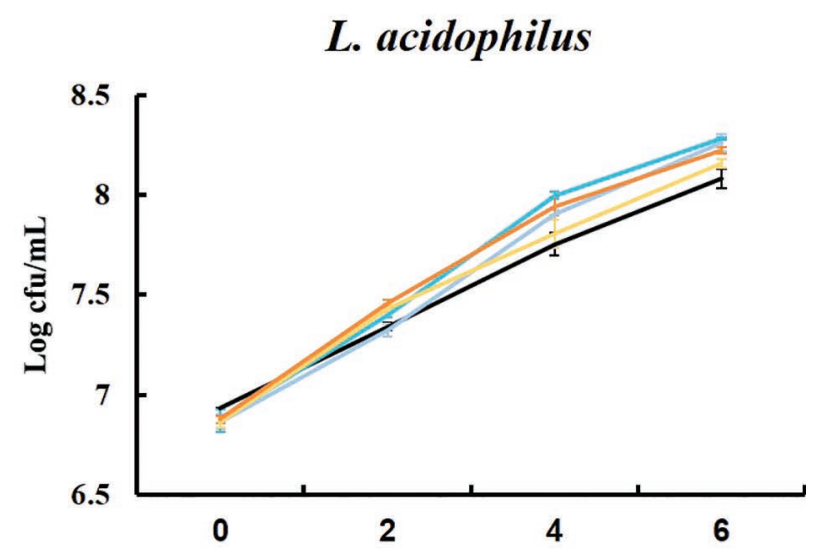

(D)

S. thermophilus

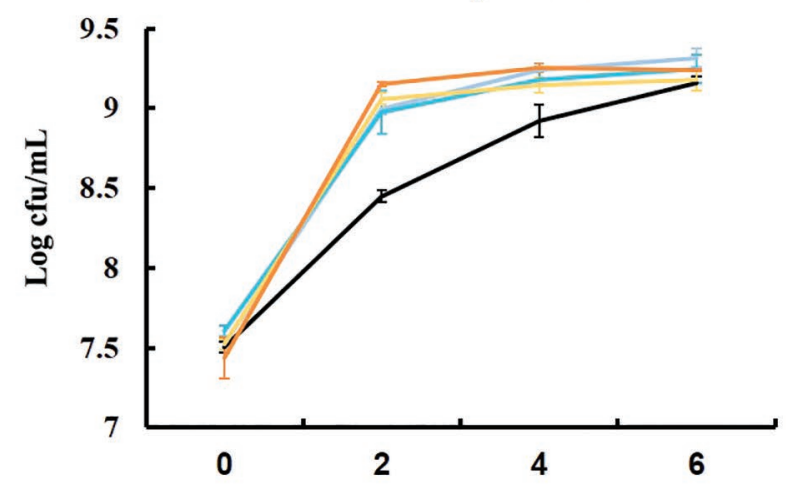

(E)

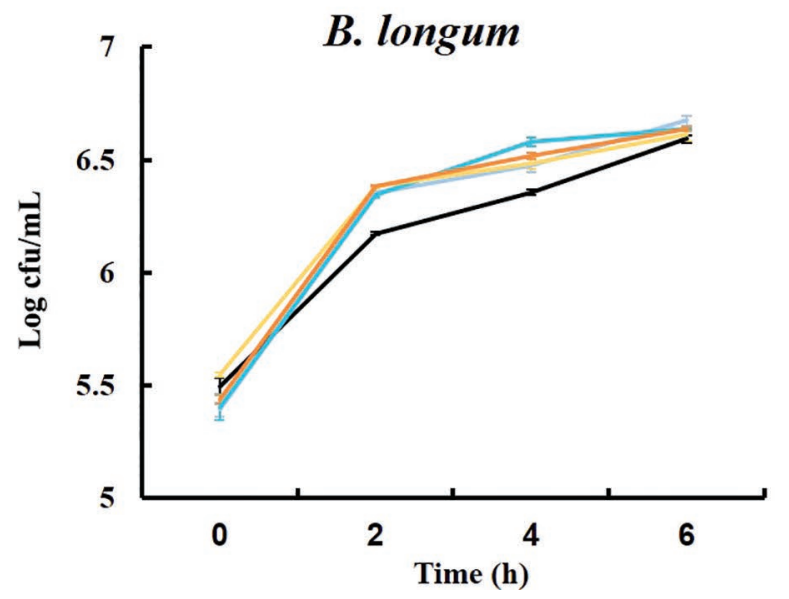

Figure 1. Changes in $\mathrm{pH}(\mathrm{A})$, acidification kinetic parameters (B), and viable counts (log cfu/mL) of lactic acid bacteria (Lactobacillus acidophilus, Streptococcus thermophilus, and Bifidobacterium longum) in yogurt-supplemented chia seed extract (CSE) during fermentation (C, $\mathrm{D}, \mathrm{E}$ ). Control = without addition of CSE (black); $0.05 \%$ and $0.1 \% \mathrm{CSWE}=0.05 \%$ and $0.1 \%$ chia seed water extract added to yogurt (blue); 0.05 and $0.1 \% \mathrm{CSEE}=0.05$ and $0.1 \%$ chia seed ethanol extract added to yogurt (red). $\mathrm{V}_{\max }=$ acidification rate; $\mathrm{t}_{\max }=$ time at which $\mathrm{V}_{\max }$ was reached; $\mathrm{t}_{\mathrm{pH} 5.0}=$ time to reach $\mathrm{pH} 5.0$; and $\mathrm{t}_{\mathrm{f}}=$ time to complete the fermentation. Results represent the mean \pm SEM, with $\mathrm{n}=3$. Bars with different letters $(\mathrm{a}-\mathrm{d})$ indicate significant differences $(P<0.05)$ within each kinetic parameter. 
(A)

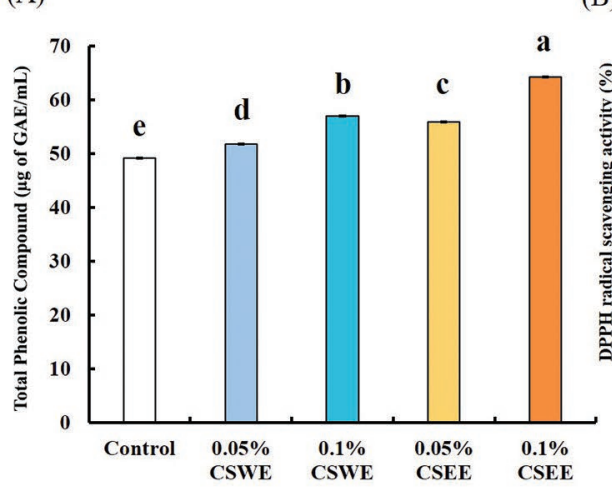

(D)
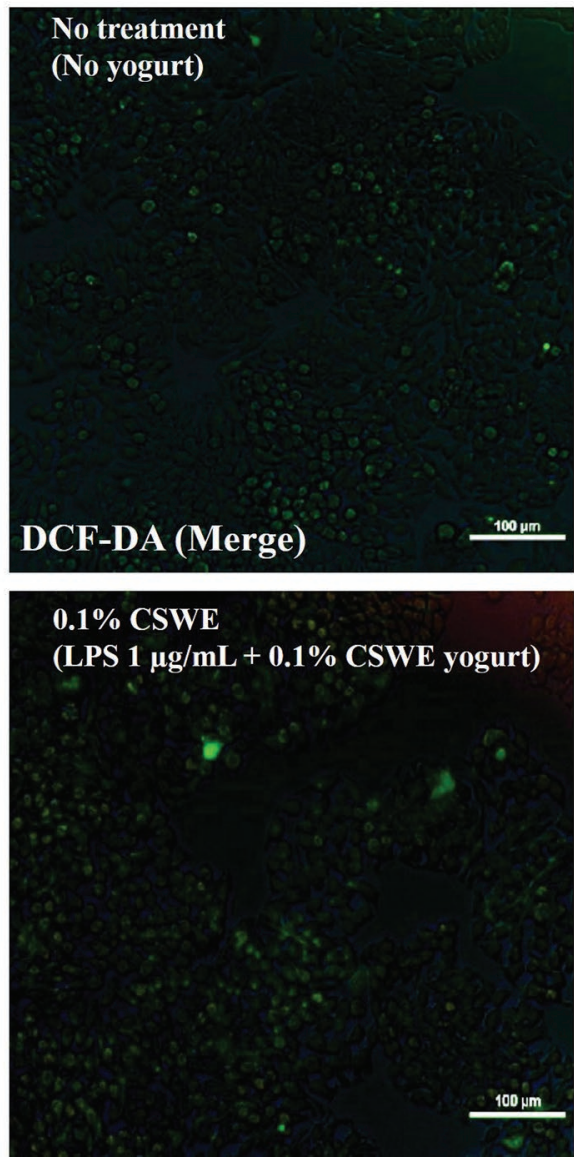

(B)
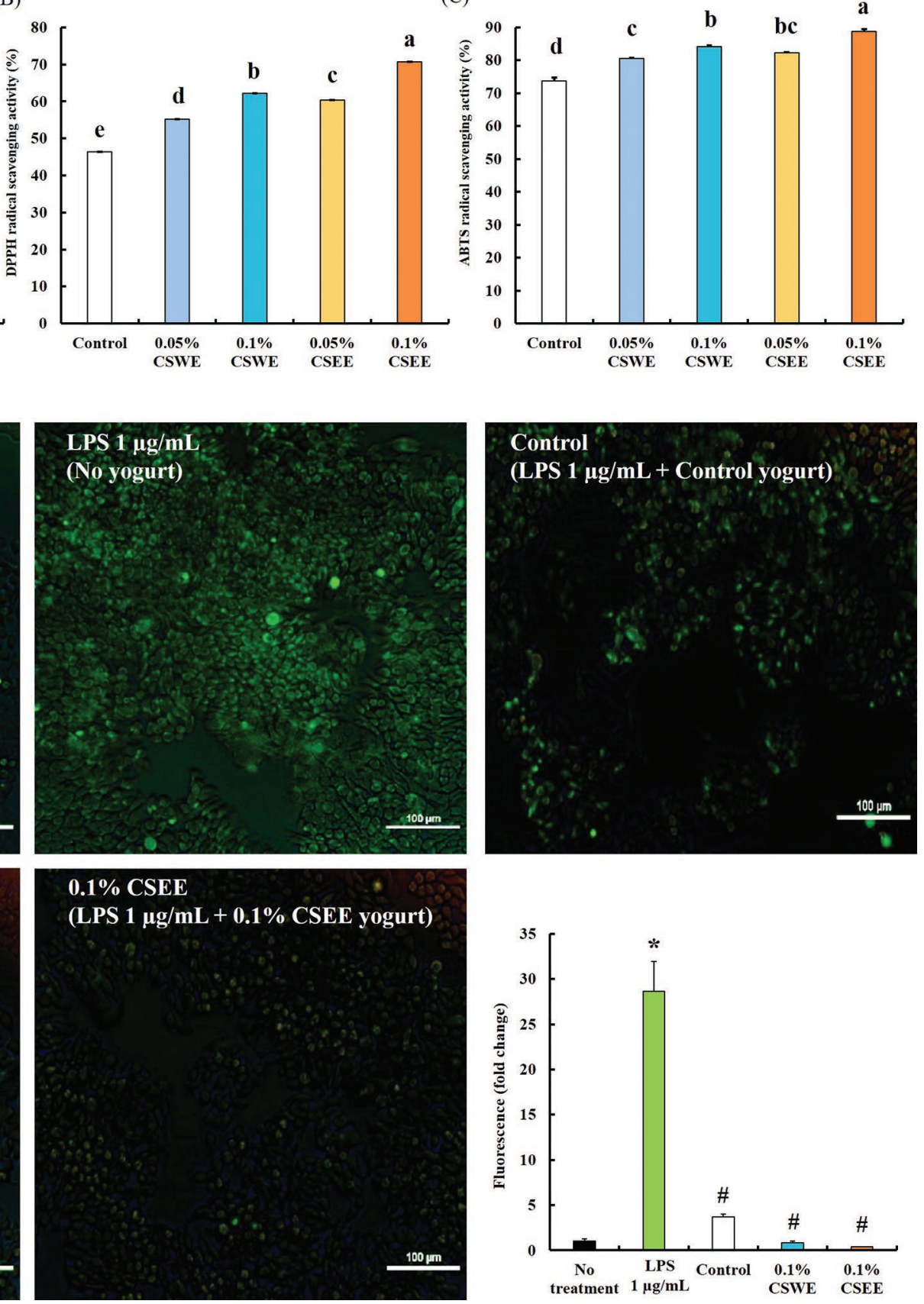

(C)

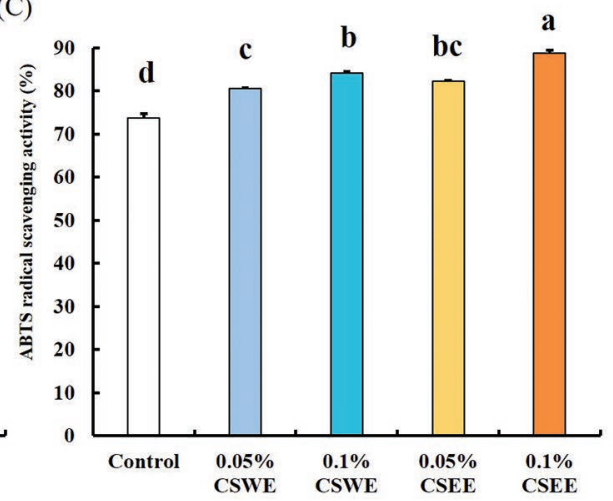

Figure 2. Total phenolic compounds (A; GAE = galic acid equivalents), radical scavenging activity of yogurt extracts using 2,2-diphenyl1-picrylhydrazyl (DPPH; B) and 2,2'-azino-bis (3-ethylbenzothiazoline-6-sulfonic acid, ABTS; C), and antioxidant effects of yogurt extracts in human colon cells, with quantification of fluorescence intensity $(\mathrm{D})$. Control $=$ no addition of chia seed extract to yogurt $\left(\mathrm{DCF}-\mathrm{DA}=2^{\prime}, 7^{\prime}\right.$-dichlorofluorescin diacetate); $0.1 \% \mathrm{CSWE}=0.1 \%$ chia seed water extract added to yogurt; $0.1 \% \mathrm{CSEE}=0.1 \%$ chia seed ethanol extract added to yogurt. The images in panel $\mathrm{D}$ are representative of 3 independent experiments. Results represent the mean $\pm \mathrm{SEM}$, with $\mathrm{n}=3$. In panels $\mathrm{A}, \mathrm{B}$, and $\mathrm{C}$, bars with different letters $(\mathrm{a}-\mathrm{e})$ indicate significant differences $(P<0.05)$. In panel $\mathrm{D}$, significant differences compared with the control (no treatment) group $\left({ }^{*} P<0.05\right)$ or LPS-only group $(\# P<0.05)$ are shown.

acid (Valdivia-López and Tecante, 2015; de Falco et al., 2017). These chia seed components show strong antioxidant and anti-inflammatory effects that can provide additional bioactive properties to yogurt. In a clinical study, ingestion of milled chia seed at $25 \mathrm{~g} / \mathrm{d}$ increased $\alpha$-linolenic acid content by $38 \%$ in the serum of postmenopausal women (Jin et al., 2012). Data from past studies also demonstrate that $\alpha$-linolenic acid 
Table 1. Color, viscosity, syneresis, and water-holding capacity (WHC) of yogurt supplemented with chia seed extracts (means \pm SD)

\begin{tabular}{|c|c|c|c|c|c|}
\hline Variable & \multicolumn{5}{|c|}{ Chia seed extract ${ }^{1}$} \\
\hline \multicolumn{6}{|l|}{ Color value ${ }^{2}$} \\
\hline$a^{*}$ & $-8.30 \pm 0.01^{\mathrm{b}}$ & $-8.30 \pm 0.01^{\mathrm{b}}$ & $-8.21^{\mathrm{a}}$ & $-8.39^{\mathrm{c}}$ & $-8.40 \pm 0.01^{\mathrm{c}}$ \\
\hline $\mathrm{b}^{*}$ & $10.66 \pm 0.02^{\mathrm{c}}$ & $10.98 \pm 0.04^{\mathrm{b}}$ & $11.42 \pm 0.04^{\mathrm{a}}$ & $11.08 \pm 0.04^{\mathrm{b}}$ & $11.40 \pm 0.02^{\mathrm{a}}$ \\
\hline Viscosity (cP) & $784.67 \pm 31.26^{\mathrm{c}}$ & $819.67 \pm 52.17^{\mathrm{bc}}$ & $900.67 \pm 52.77^{\mathrm{ab}}$ & $853.67 \pm 21.55^{\mathrm{bc}}$ & $952 \pm 26.46^{\mathrm{a}}$ \\
\hline
\end{tabular}

${ }^{\mathrm{a}-\mathrm{c}}$ Means with different superscript letters within a row indicate significant differences $(P<0.05)$.

${ }^{1}$ Control $=$ no chia seed extract addition; $0.05 \%$ and $0.1 \%$ CSWE $=0.05 \%$ and $0.1 \%$ chia seed water extract added to yogurt; $0.05 \%$ and $0.1 \%$ CSEE $=0.05 \%$ and $0.1 \%$ chia seed ethanol extract added to yogurt.

${ }^{2} \mathrm{~L}^{*}=$ darkness-lightness ( 0 to 100$) ; \mathrm{a}^{*}=$ greenness-redness $(-60$ to 60$) ; \mathrm{b}^{*}=$ blueness-yellowness $(-60$ to 60$)$.

inhibits inflammation by decreasing inflammatory mediators (e.g., IL-6, IL-8, cyclooxygenase-2, and tumor necrosis factor- $\alpha$ ) in human colon epithelial cells and IBD-induced rats (Reifen et al., 2015). The antioxidant effects of chia seed contributed to a decrease in DNA strand scission induced by hydroxyl and peroxyl radicals and increased the plasma antioxidant enzymes (da Silva Marineli et al., 2015; Rahman et al., 2017). Another major chia seed component, chlorogenic acid, and its metabolite caffeic acid attenuated dextran sulfate sodium-induced colitis in mice, and decreased IL-8 in human colon epithelial cells (Shin et al., 2015). Furthermore, chlorogenic acid decreased intestinal ROS and inflammation in rats (Zhou et al., 2016). Because oxidative stress and inflammation are major contributors to the initiation and development of IBD, our data suggest that ingestion of CSE-supplemented yogurt may protect against such intestinal disease. Taken together, our data indicate that yogurt supplemented with CSE enhances antioxidant activity in colon epithelial cells due to bioactive components in chia seed and that the ingestion of CSE-supplemented yogurt can improve colon health.

In conclusion, supplementation of yogurt with chia seed extract shortened the fermentation time and increased LAB counts. Furthermore, the physicochemical properties (i.e., viscosity, syneresis, WHC, and color) and antioxidant effects of cells were significantly improved in yogurt supplemented with chia seed extracts. This work highlights the enhanced quality characteristics and beneficial effects of CSE-supplemented yogurt on colon health.

\section{ACKNOWLEDGMENTS}

The authors have no funding to report and declare no conflicts of interest.

\section{REFERENCES}

Amaya-Llano, S., A. Martínez-Alegría, J. Zazueta-Morales, and F. Martínez-Bustos. 2008. Acid thinned jicama and maize starches as fat substitute in stirred yogurt. Lebensm. Wiss. Technol. 41:12741281.

Aryana, K. J., and P. McGrew. 2007. Quality attributes of yogurt with Lactobacillus casei and various prebiotics. Lebensm. Wiss. Technol. 40:1808-1814.

Asioli, D., J. Aschemann-Witzel, V. Caputo, R. Vecchio, A. Annunziata, T. Næs, and P. Varela. 2017. Making sense of the "clean label" trends: A review of consumer food choice behavior and discussion of industry implications. Food Res. Int. 99:58-71.

Bhattacharyya, A., R. Chattopadhyay, S. Mitra, and S. E. Crowe. 2014. Oxidative stress: An essential factor in the pathogenesis of gastrointestinal mucosal diseases. Physiol. Rev. 94:329-354.

Cardona, F. C. Andrés-Lacueva, S. Tulipani, F. J. Tinahones, and M. I. Queipo-Ortuño. 2013. Benefits of polyphenols on gut microbiota and implications in human health. J. Nutr. Biochem. 24:1415-1422.

Coelho, M. S., and M. de las Mercedes Salas-Mellado. 2015. Effects of substituting chia (Salvia hispanica L.) flour or seeds for wheat flour on the quality of the bread. Lebensm. Wiss. Technol. 60:729-736.

da Silva Marineli, R., S. A. Lenquiste, E. A. Moraes, and M. R. Maróstica Jr. 2015. Antioxidant potential of dietary chia seed and oil (Salvia hispanica L.) in diet-induced obese rats. Food Res. Int. 76:666-674.

de Falco, B., M. Amato, and V. Lanzotti. 2017. Chia seeds products: An overview. Phytochem. Rev. 16:745-760.

Dimitrova, K., and Y. Kartalska. 2015. Technological characteristics of yogurt supplemented with $3 \%$ ground amaranth seeds during refrigerated storage. Appl. Sci. Rep. 12:27-32.

Dönmez, Ö., B. A. Mogol, and V. Gökmen. 2017. Syneresis and rheological behaviors of set yogurt containing green tea and green coffee powders. J. Dairy Sci. 100:901-907.

García-Pérez, F., Y. Lario, J. Fernández-López, E. Sayas, J. PérezAlvarez, and E. Sendra. 2005. Effect of orange fiber addition on yogurt color during fermentation and cold storage. Color Res. Appl. 30:457-463.

Jeong, C. H., H. Ryu, T. Zhang, C. H. Lee, H. G. Seo, and S. G. Han. 2018. Green tea powder supplementation enhances fermentation and antioxidant activity of set-type yogurt. Food Sci. Biotechnol. 27:1419-1427.

Jin, F., D. C. Nieman, W. Sha, G. Xie, Y. Qiu, and W. Jia. 2012. Supplementation of milled chia seeds increases plasma ALA and EPA in postmenopausal women. Plant Foods Hum. Nutr. 67:105-110.

Jung, J., H.-D. Paik, H. J. Yoon, H. J. Jang, R. K. C. Jeewanthi, H.-S. Jee, X. Li, N.-K. Lee, and S.-K. Lee. 2016. Physicochemical characteristics and antioxidant capacity in yogurt fortified with red ginseng extract. Korean J. Food Sci. Anim. Resour. 36:412. 
Kabir, F., M. S. Sultana, and H. Kurnianta. 2015. Polyphenolic contents and antioxidant activities of underutilized grape (Vitis vinifera L.) pomace extracts. Prev. Nutr. Food Sci. 20:210.

Li, S., G. Gong, C. Ma, Z. Liu, and J. Cai. 2016. Study on the influence of tea extract on probiotics in skim milk: From probiotics propagation to metabolite. J. Food Sci. 81:M1981-M1986.

Muñoz, L. A., A. Cobos, O. Diaz, and J. M. Aguilera. 2013. Chia seed (Salvia hispanica): An ancient grain and a new functional food. Food Rev. Int. 29:394-408

Nielsen, S. D., R. L. Beverly, Y. Qu, and D. C. Dallas. 2017. Milk bioactive peptide database: A comprehensive database of milk protein-derived bioactive peptides and novel visualization. Food Chem. 232:673-682.

Oh, N. S., J. Y. Lee, J. Y. Joung, K. S. Kim, Y. K. Shin, K.-W. Lee, S. H. Kim, S. Oh, and Y. Kim. 2016. Microbiological characterization and functionality of set-type yogurt fermented with potential prebiotic substrates Cudrania tricuspidata and Morus alba L. leaf extracts. J. Dairy Sci. 99:6014-6025.

Ozdal, T., E. Capanoglu, and F. Altay. 2013. A review on protein-phenolic interactions and associated changes. Food Res. Int. 51:954970.

Ozturkoglu-Budak, S., C. Akal, and A. Yetisemiyen. 2016. Effect of dried nut fortification on functional, physicochemical, textural, and microbiological properties of yogurt. J. Dairy Sci. 99:8511-8523.

Pandey, K. R., S. R. Naik, and B. V. Vakil. 2015. Probiotics, prebiotics and synbiotics - A review. J. Food Sci. Technol. 52:7577-7587.

Pellegrini, M., R. Lucas-Gonzalez, E. Sayas-Barberá, J. FernándezLópez, J. A. Pérez-Álvarez, and M. Viuda-Martos. 2018. Bioaccessibility of phenolic compounds and antioxidant capacity of chia (Salvia hispanica L.) seeds. Plant Food Hum. Nutr. 73:47-53.

Peluso, I., L. Romanelli, and M. Palmery. 2014. Interactions between prebiotics, probiotics, polyunsaturated fatty acids and polyphenols: diet or supplementation for metabolic syndrome prevention? Int. J. Food Sci. Nutr. 65:259-267.

Pessione, E., and S. Cirrincione. 2016. Bioactive molecules released in food by lactic acid bacteria: encrypted peptides and biogenic amines. Front. Microbiol. 7:876

Pintado, T., A. M. Herrero, F. Jiménez-Colmenero, and C. Ruiz-Capillas. 2016. Strategies for incorporation of chia (Salvia hispanica L.) in frankfurters as a health-promoting ingredient. Meat Sci. 114:75-84.

Pop, C., R. Vlaic, A. Fărcaş, L. Salanță, D. Ghicăşan, C. Semeniuc, and A. M. Rotar. 2015. Influence of pollen, chia seeds and cranberries addition on the physical and probiotics characteristics of yogurt. Bull. UASVM Food Sci. Technol. 72:141-142.

Rahman, M. J., A. C. de Camargo, and F. Shahidi. 2017. Phenolic and polyphenolic profiles of chia seeds and their in vitro biological activities. J. Funct. Foods 35:622-634.

Rawel, H. M., D. Czajka, S. Rohn, and J. Kroll. 2002. Interactions of different phenolic acids and flavonoids with soy proteins. Int. J. Biol. Macromol. 30:137-150.

Reifen, R., A. Karlinsky, A. H. Stark, Z. Berkovich, and A. Nyska. 2015. $\alpha$-Linolenic acid (ALA) is an anti-inflammatory agent in inflammatory bowel disease. J. Nutr. Biochem. 26:1632-1640.
Sah, B., T. Vasiljevic, S. McKechnie, and O. Donkor. 2014. Effect of probiotics on antioxidant and antimutagenic activities of crude peptide extract from yogurt. Food Chem. 156:264-270.

Sah, B., T. Vasiljevic, S. McKechnie, and O. Donkor. 2016. Physicochemical, textural and rheological properties of probiotic yogurt fortified with fibre-rich pineapple peel powder during refrigerated storage. Lebensm. Wiss. Technol. 65:978-986.

Santana-Gálvez, J., L. Cisneros-Zevallos, and D. A. Jacobo-Velázquez. 2017. Chlorogenic acid: Recent advances on its dual role as a food additive and a nutraceutical against metabolic syndrome. Molecules 22:358.

Sargi, S. C., B. C. Silva, H. M. C. Santos, P. F. Montanher, J. S. Boeing, S. Júnior, O. Oliveira, N. E. Souza, and J. V. Visentainer. 2013. Antioxidant capacity and chemical composition in seeds rich in omega-3: chia, flax, and perilla. Food Sci.Technol. (Campinas) $33: 541-548$

Shin, H. S., H. Satsu, M.-J. Bae, Z. Zhao, H. Ogiwara, M. Totsuka, and M. Shimizu. 2015. Anti-inflammatory effect of chlorogenic acid on the IL- 8 production in Caco- 2 cells and the dextran sulphate sodium-induced colitis symptoms in C57BL/6 mice. Food Chem. 168:167-175.

Sun-Waterhouse, D., J. Zhou, and S. S. Wadhwa. 2013. Drinking yoghurts with berry polyphenols added before and after fermentation. Food Control 32:450-460.

Ullah, R., M. Nadeem, A. Khalique, M. Imran, S. Mehmood, A. Javid, and J. Hussain. 2016. Nutritional and therapeutic perspectives of Chia (Salvia hispanica L.): A review. J. Food Sci. Technol. $53: 1750-1758$.

Ünal, G., and A. S. Akalin. 2013. Influence of fortification with sodium-calcium caseinate and whey protein concentrate on microbiological, textural and sensory properties of set-type yoghurt. Int. J. Dairy Technol. 66:264-272.

Valdivia-López, M. Á., and A. Tecante. 2015. Chia (Salvia hispanica): A review of native mexican seed and its nutritional and functional properties. Adv. Food Nutr. Res. 75:53-75.

Vecchio, R., E. J. Van Loo, and A. Annunziata. 2016. Consumers willingness to pay for conventional, organic and functional yogurt: evidence from experimental auctions. Int. J. Consum. Stud. 40:368-378

Zare, F., J. Boye, V. Orsat, C. Champagne, and B. Simpson. 2011 Microbial, physical and sensory properties of yogurt supplemented with lentil flour. Food Res. Int. 44:2482-2488.

Zhang, T., C. H. Jeong, W. N. Cheng, H. Bae, H. G. Seo, M. C. Petriello, and S. G. Han. 2019. Moringa extract enhances the fermentative, textural, and bioactive properties of yogurt. Lebensm. Wiss. Technol. 101:276-284.

Zhou, Y., L. Zhou, Z. Ruan, S. Mi, M. Jiang, X. Li, X. Wu, Z. Deng, and Y. Yin. 2016. Chlorogenic acid ameliorates intestinal mitochondrial injury by increasing antioxidant effects and activity of respiratory complexes. Biosci. Biotechnol. Biochem. 80:962-971. 